\title{
Leveraging Integrated Bike-Sharing with Existing Bus Rapid Transit (BRT) to Reduce Motor Vehicle in Central Jakarta Municipal
}

\author{
D. Daniella ${ }^{a}$, A. A. Dharma Wangsa ${ }^{a}$ \\ a Indonesian Surveyors Association, Indonesia
}

\section{Article Info:}

Received: 10 August 2018

in revised form: 10 January 2019

Accepted: 30 March 2019

Available Online: 30 August 2019

\section{Keywords:}

BRT, walking distance, bike-

sharing

\section{Corresponding Author:}

Daniella

Indonesian Surveyors Association,

Indonesia

Email:

danielladaril@gmail.com

\begin{abstract}
Jakarta is one of the most congested cities in the world due to a plethora of motor vehicles used in the city. One of the government actions to address the issue is by implementing Bus Rapid Transit (BRT) as an alternative public transportation mode. However, according to the convenience walking distance standard, the BRT coverage the inhabitant to choose motor vehicle rather than walking. This paper purposes Bike-Sharing as the smart transportation mode to overcome such issue and predict the three potential places to establish sharing-bike stations according to the convenience walking distance standard. In this paper the walking distance is classified into 100 mater range (300 meter, 400 meter and 500 meter) projected using the euclidean distance principle. As the result for 300 meter standard, there are 809 potential bikesharing stations consist of 164 main stations and 645 feeder stations, while the 400 meter standard needs 541 potential stations with 140 stations serve the BRT station directly and 401 stations as the feeder. Furthemore, with 500 meter standard, 359 stations consist of 131 main stations and 228 feeder stations is needed.
\end{abstract}

Copyright $(0) 2019$ GJGP-UNDIP This open access article is distributed under a Creative Commons Attribution (CC-BY-NC-SA) 4.0 International license.

Daniella, D., \& Dharma Wangsa, A.A. (2019). Leveraging Intergated Bike-Sharing With Existing Bus Rapid Transit (BRT) to Reduce Motor in Central Jakarta Municipal. Geoplanning: Journal of Geomatics and Planning, 6(1), 13-20. doi: 10.14710/geoplanning.6.1.13-20

\section{INTRODUCTION}

Bike-sharing and Bus Rapid Transit (BRT) have gained popularity in a plethora of countries as the cost effective, convenient alternative transportation modes with high flexibilities that help cities to reduce congestion. Bike-sharing and BRT can complement each other. Along with BRT (as the public transportation), bike-sharing is the answer to the urban infrastructure since it gives environmental, economic and social benefits, including flexible mobility, lower emission levels, health benefits, reduced congestion, lower financial cost and support for more integrated transport connections (Mateo-Babiano, 2015).

Nowadays, cities had established their own bike-sharing and BRT system, some of them integrate their bike-sharing system with Bus Rapid Transit (BRT) to comply the demand from a larger distance. Paris is one of the cities that has the most inspiring bike-sharing system in the world while Guangzhou is the world role model for its integrated BRT bike-sharing system. The experiences of these cities to manage their bike-sharing and integrate it with BRT system are the good references to implement the integrated BRT bike-sharing system, particularly in the cities which have no bike-sharing system like cities in Jakarta.

Jakarta is one of the world most gridlocked cities. The high number of motor vehicle users is one of the reasons to this congestion. According to the data from the police in 2012 there were about 14.6 million of motor vehicles were used in Jakarta, consisted of 10.8 million motorbikes and 3.8 million automobiles and the number is increase $24 \%$ into 18.1 million users consisted of 13.4 million motorbikes and the remaining 4.7 million automobiles (BPS-Statistics of DKI Jakarta Province, 2017). The congestion burdening city with the loss, if this issue is not addressed yet The National Development Planning Agency (Bappenas) predict that throughout 2020 Jakarta would loss its economic around 65 trillion (US\$ 4.48 billion) (Japan International Cooperation Agency (JICA) \& Badan Perencana Pembangunan Nasional (Bappenas) Republik Indonesia, 2004). 
In order to reduce the congestion, in 2004 the Jakarta Government had established BRT as an alternative public transportation mode. However, according to the World Bank urban transport service quality standard and according to the Indonesian Directorate General of Land Transportation, the convenient walking distance to bus stops in dense urban areas are $300-500$ m (World Bank, 1987; Departemen Perhubungan Republik Indonesia, 2002). Thus the BRT coverage area is not sufficient enough, particularly to cover Central Jakarta Municipal, and it could be a potential seed for the inhabitant to choose motor vehicle rather than walking.

The aim of this research is to cover the lack of BRT coverage by integrating the cost effective and environmental friendly vehicle, bike-sharing, with the existing BRT. The coverage of bike-sharing expected to be implemented for the whole city municipal (like in Paris) then expected to be integrated with the existing BRT, similar to Guangzhou. Additionally according to the recent studies, bike-sharing has both direct impact by reducing the automobile usage (DeMaio, 2009; Martin \& Shaheen, 2014) and indirect impact by increasing the public transport usage by connecting its first mile-last mile (Fishman et al., 2013; Noland \& Ishaque, 2006; Shaheen, et al, 2013) Hence integrated bike-sharing with BRT is highly suggested to cover the gap between BRT and places in Central Jakarta.

\section{DATA AND METHODS}

The data used in this paper were gathered by comprehensive literature study, extracted from the transport tracker application (Trafi) that cooperate with Transjakarta (BRT in Jakarta) and from Map of DKI Jakarta Regional Spatial Planning 2010 - 2030 as well. From the literature study the data gathered are the characteristics of bike-sharing systems and its integration with BRT in Paris and Guangzhou respectively, while from the transport tracker application, the main BRT stations and the feeder stations of BRT in Central Jakarta Municipal are extracted. Moreover the road Masterplan of Central Jakarta Municipal is extracted from the Map of DKI Jakarta Regional Spatial Planning 2010 - 2030.

Firstly, this study is conducted to identify the successful behind bike-sharing system and its integration to BRT in cities that have popular success in each system. Then, this study attempts to implement these systems in Central Jakarta to reduce the motor vehicle usage by implementing the standard that has been determined and adjust it with the city's long-term road master plan. Since the walking distance standard is 300-500 meters, in this paper it is classified into 100 meter range distance (300 meter, 400 meter and 500 meter) and projected using the Euclidean distance principle. The study area of this paper is focused on the Jakarta's second most populous city in Jakarta, Municipal of Central Jakarta, with 19,068 people per square kilometer in $48.13 \mathrm{~km} 2$ land area (BPS-Statistics of DKI Jakarta Province, 2017). The research held in June 2018, and according to the data observed, there are 173 active BRT stations in Municipal of Central Jakarta, consists of 48 main stations and 125 feeder stations. According to the 300 meter walking distance standard, the BRT cover $20.88 \mathrm{~km} 2$ (43.38\%) area of Central Jakarta, leaving more than half of the city with lack of walking distance coverage. While with 400 meter and 500 meter walking distance the BRT cover $27.78 \mathrm{~km} 2$ $(57.72 \%)$ and $33.11 \mathrm{~km} 2(68.8 \%)$ of the Central Jakarta land area respectively, resulting more than $40 \%$ and more than $30 \%$ of the city is unreachable by the pedestrian. The projections of this coverage area are shown in Figure 1.

The methods used in this study are literature study and desktop study to determine the potential bikesharing stations with respect to 300 meter, 400 meter and 500 meter walking distance standard that had been previously classified. Furthermore, the desktop study conducted to adjust the potential bike sharing station distribution with the Central Jakarta long-term road master plan as well in order to gain the sustainable urban transport plan. According to the Indonesian Ministry of Public Works Regulation, minimum width of bike lane share with a pedestrian lane that flanked by buildings on both sides is 3.5 meter (Kementerian Pekerjaan Umum Republik Indonesia, 2014). Meanwhile the space for bike sharing station needed is approximately 2 meter wide (ITDP, 2014), thus the minimum 5.5 meter lane width is needed for the system to operate well. Basically, there are two types of bike-sharing; smart bikes (with on-bike checkout capabilities) and smart docks (bikes are located at stations with docks and payment kiosks. Due to the high consideration to the risk of theft and vandalism in Central Jakarta Municipal, the type of bike-sharing docs are chosen in this paper (both of this type of Bike-sharing is shown in Figure 2). 


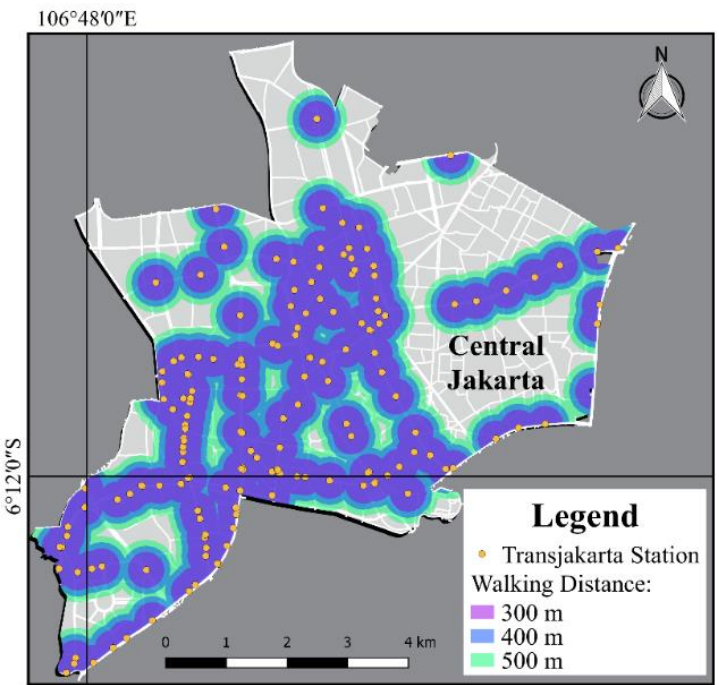

Figure 1. Coverage area discovered by Transjakarta in Central Jakarta Municipal.

(a)

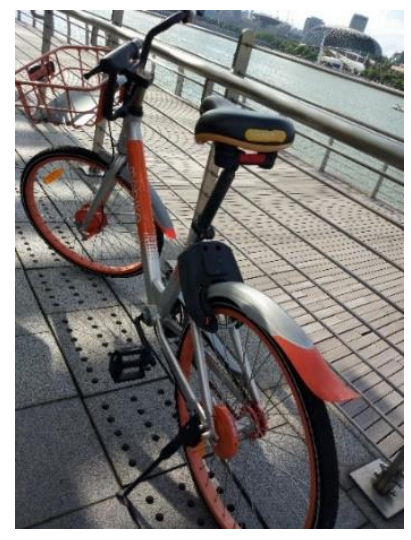

(b)

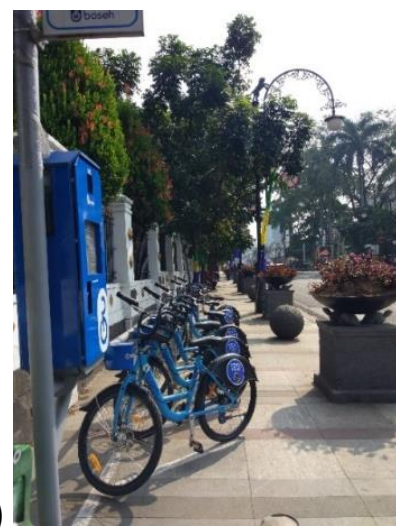

Figure 2. Type of bike-sharing; (a) smart bike in Singapore named Mobike, (b) Bosech, a smart dock in Bandung, Indonesia.

Similar to BRT, this bike-sharing station docks consist of the main station and feeder station. The main station is the bike-sharing station that is installed next to the BRT station, which have the main purpose to aid the passenger from Transjakarta station to reach their travel destinations, while the feeder station is installed next to the other feeder station with the range is limited to the walking distance standard in every place in Central Jakarta. This station has the aim as the feeder for the inhabitant to reach BRT station by cycling instead of riding a motor vehicle. Thus the first mile - last mile connection to become easier in every place in the Central Jakarta Municipal and people have the same opportunity to use the nearby bike-sharing. Furthermore, in this paper the bike-sharing system will be modelled using Euclidean projection to find the appropriate bike station that cover the city municipal in three different walking distance standard (300 $\mathrm{m}$, $400 \mathrm{~m}$ and $500 \mathrm{~m}$ ) as mentioned before. All of the advantages and disadvantages between the walking distances used will be elaborated and the better walking distance and its potential places to establish bikesharing stations then will be suggested.

\section{RESULTS AND DISCUSSION}

\subsection{Bike-sharing and BRT around the world}

Access and mobility are the key not only about sustainable mobility, but also for sustainable development. Cities in a different country has choose bike-sharing and BRT as their most cost-effective transportation. Paris and Guangzhou are the most popular cities with a good system of bike-sharing and integrated Bike-sharing - BRT systems that worth to be followed. A Plethora of cities held the comprehensive research study of the successful system they create before establishing their own system. In terms of bike- 
sharing, Vélib' have been one of the largest bike-sharing schemes in the world that cover the whole of its city. In 2007, Paris launched Vélib' with 7,000 bikes at 750 stations across the city and gaining an average of 75,000 trips per day in the first year, with peak days exceeding well over 100,000 riders (ITDP, 2014). The following year, the bike-sharing station almost doubled into 1,200 stations and rising their number of bicycles into 16,000 and nowadays it has over 21,000 bicycles at well over 1,800 different Vélib' stations (ITDP, 2014). These numbers show that the number of bike-sharing station in the city is keep growing, reflecting that the city have the eager to serve more and more user through the city.

Gaining that success needs the forceful commitment from the government, roughly 4,000 parking bays were removed to accommodate 1,451 new Vélib' stations that hold about 20,000 bike-sharing (Kodransky \& Hermann, 2010). Furthermore, to assure its station distribution quality the city used one station every 300 meters (28 kiosks every one square mile) as a guideline for the first phase of its bike-sharing system (ITDP, 2014; New York City Department of City Planning, 2009). This standard is embraced by cities around the world in their upcoming bike-sharing system. Although Paris bike-sharing system is not integrated with BRT system, but it has a good enough standard to be followed, Paris standard of bike sharing (e.g. station density standard) still can be leveraged to distinguish the potential bike-sharing station locations.

Nowadays, cities have a tendency to integrate their Bike-sharing and BRT stations, Guangzhou, China, is the popular cities operating this system due its winning of Sustainable Transport Award of its BRT and integrated bike sharing system in 2011. This bike-sharing system named Guangzhou Public Bicycle. Guangzhou first phase of bike-sharing system has been developed along the city's BRT corridor to serve demand for the upcoming Asian Games (United Nations Department of Economic and Social Affairs, 2011).

This system is initially set up in June 22, 2010 and launched with 1,000 vehicles and 18 docking stations, as of December 2016 the system contained 8,850 bicycles and more than 110 docking stations (Han, et al., 2018). This system is grown and recorded in May 2013, this system had covered 263 square kilometre area that had a population density about 1,708 people per square kilometre (ITDP, 2014). The system received a warm welcome from the general public since it was put into use, a total of $35,382,400$ trips have been made using this service (Han et al., 2018).

Despite having a good commitment from the Guangzhou government, this integrated system has gained the success since its serious consideration of user convenience in its technical Masterplan. For instance, to encourage the BRT user leveraging this bike-sharing, Guangzhou has the integrated payment card named YongChengTong. This smart card served the integrated payment not only for bike-sharing, but also BRT/bus and Metro as well. Thus attract the user by making the payment simpler and easier across different modes of public transport. Furthermore, the Guangzhou station-density parameter guideline is adjusted according to the field needs. This bike-sharing system are needed on both sides of the corridor since the only way for the users to cross the corridor is through pedestrian bridges, which would require carrying the bicycle up flights of stairs to get to the other side (ITDP, 2014). Meanwhile the park area has no station, since forbidden. Thus, the density stations along the corridor is much higher than recommended ratio and the park area seems to be clear. Even though Guangzhou bike-sharing system does not connect the whole city yet, its integrated standard with BRT (e.g. the placement of stations regulation and the integrated payment system) system is very good enough to be adopted. Combination of Paris bike sharing that cover the whole city and Guangzhou standard of bike-sharing-BRT integration provides the whole city guideline of bike-sharing-BRT integrated system.

\subsection{Potential Bike Sharing Stations in The Central of Jakarta}

Transjakarta is the world's longest BRT route at $134 \mathrm{~km}$ (Sustainability Management Capstone, 2013). Based on the data, overall this BRT station only covers $50 \%$ to $70 \%$ of the Central Jakarta Municipal area while the reminder $30 \%$ to $50 \%$ of its area is too far enough to reach through walking. This gap can be fulfilled by integrating the system with bike-sharing. Adopting the Paris and Guangzhou systems and adjust it with Indonesian existing regulation and road long term master plan. The potential bike-sharing spot in Central Jakarta Municipal can be shown in Figure 3. 
(a)

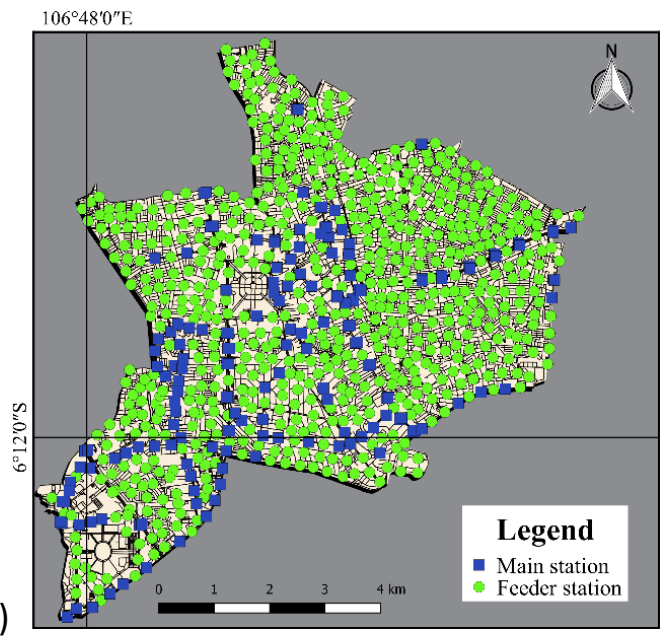

(b)

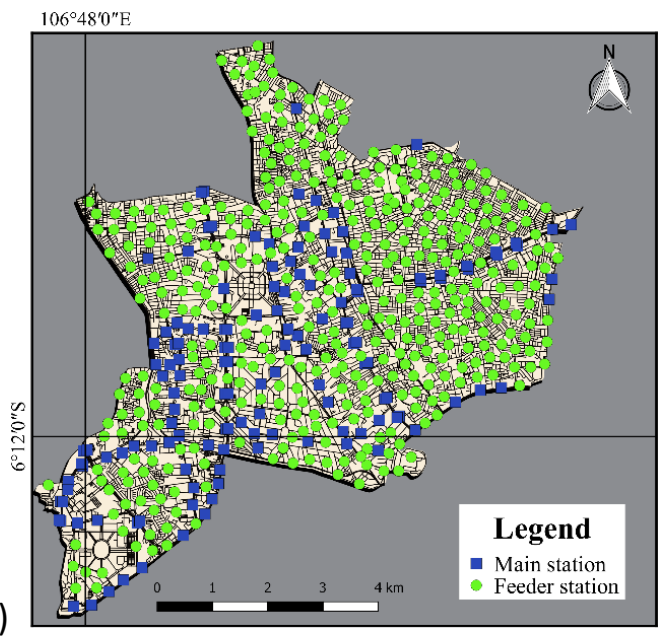

(c)

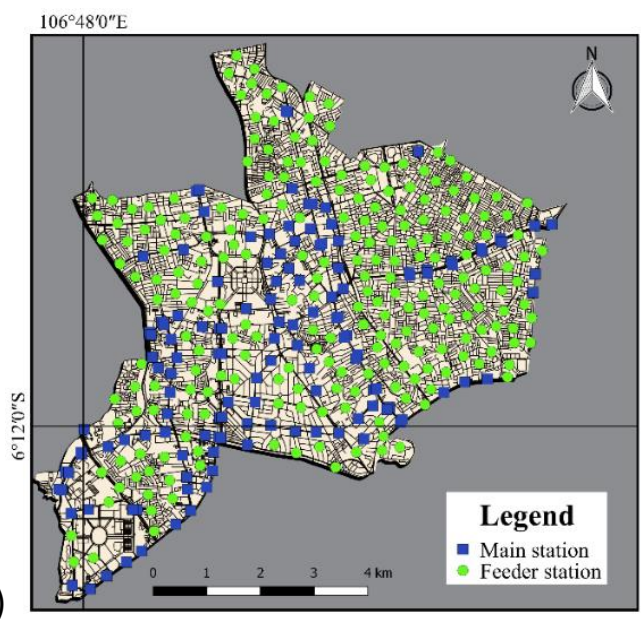

Figure 3. Potential bike-sharing station based on; (a) 300 meter walking distance, (b) 400 meter walking distance and (c) 500 meter walking distance

According to the result of potential bike sharing stations, with 300 meter walking distance standard, Figure 3 (a), there are 809 potential bike-sharing stations consist of 164 main stations and 645 feeder bikesharing stations. Hereafter the potential bike-sharing stations with 100 meter larger coverage walking standard $(400 \mathrm{~m})$ eliminate more than 250 potential stations into 541 potential stations with 140 stations serve the BRT station directly while the remaining 401 stations serve the BRT stations as the feeder stations. The distribution of these potential spots with 400 meter walking distance is shown in Figure 3 (b). Furthermore, with 500 meter standard, Figure 3 (c), the city needs 359 bike-sharing stations consist of 131 stations that easily can be reached by walking from the BRT stations and 228 bike-sharing feeder stations (almost decrease $50 \%$ from the previous standard). Based on the result, the greater the walking distance standard the less number of potential bike stations needed to be installed.

In order to satisfy the requirement, all of the potential bike-sharing had adjusted based on city's road master plan with 5.5 meter minimum lane width. Although the long-term road master plan lane width is chosen rather than the existing lane width, however the existing paved road still becomes the big consideration to choose all of the spots. These lane widths where the bike-sharing stations are potentially to be spotted according to the Figure 3 (a), (b) and (c) are shown in Figure 4. In the figure the lane widths where the stations are potentially to be installed with 300 meter standard illustrated with red dots, while the orange short dash line and blue long dash line show the lane widths of stations with 400 meter and 500 meter walking distance standard respectively. The threshold of suggested lane width (5.5 meter) is shown in figure as green line. According to the data adjusted, the lane width varies from 6 meters to 101 meters and none of them spotted under 5.5 lane width. Thus, these potential spots that suggested have a greater lane width than suggested and suitable to install the stations. 


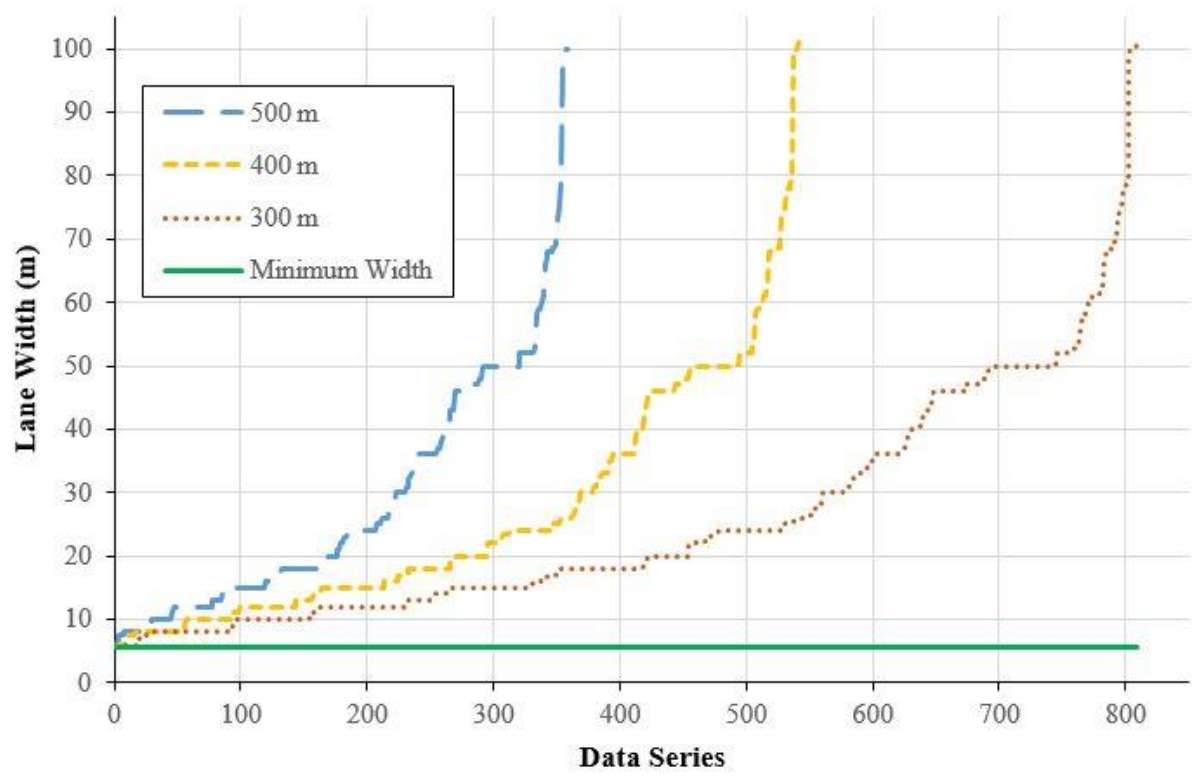

Figure 4. Lane width of data series.

According to the result the greater the walking distance standard the more area of the Central Jakarta Municipal is covered. Since there are prohibited area to install bike stations in Central Jakarta, the gap between stations does still exist. The coverage is just a slightly different, for $\mathbf{3 0 0}$ meter standard there are 47.75 square kilometres (99.21\%) area covered, while with 400 meter and 500 meter walking distance standards cover $99.87 \%(48.07 \mathrm{~km} 2)$ and $99.91 \%$ (48.09 $\mathrm{km} 2)$ of the Central Jakarta Municipal area respectively. Furthermore, the lane width is classified to find out their quantity in order to see the percentage of lane width used in this research. The percentage of the lane width chosen for 300 meter, 400 meter and 500 meter standard, shown as red dots, orange short dash line and blue long dash line respectively in Figure 5. According to the Figure 5 the greater the walking distance standard, the less narrow lane used. The lane with 6 meter to 15 meter width is slightly different, but around $40 \%$ for 300 and 400 meter standard, while for 500 meter walking distance, the station that is suggested to be installed in the 6 meter to 15 meter lane width is about $33 \%$ of the suggestions. Meanwhile, in the 36 to 55 meter lane width the potential stations are more dominated by 500 meter standard rather than 300 meter and 400 meter standard and the deviation tends to be constant around $3 \%$. Thus 500 meter standard increase the possibility of station installation in a more proper area which have a high level of security.

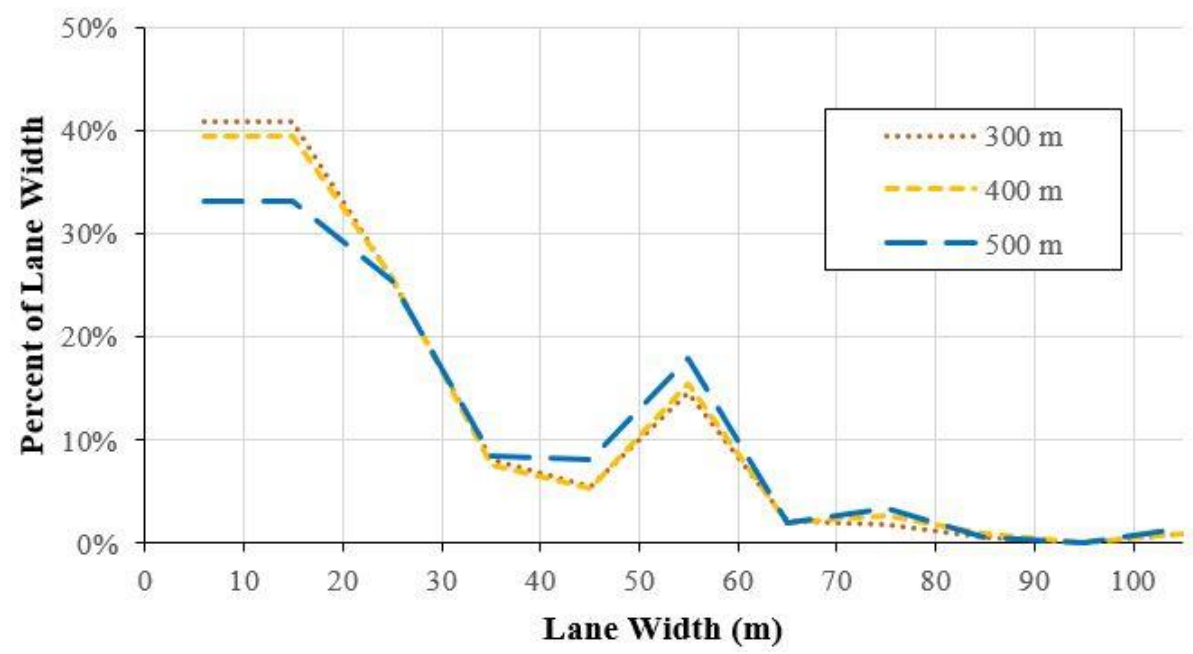

Figure 5. Lane width quantity 


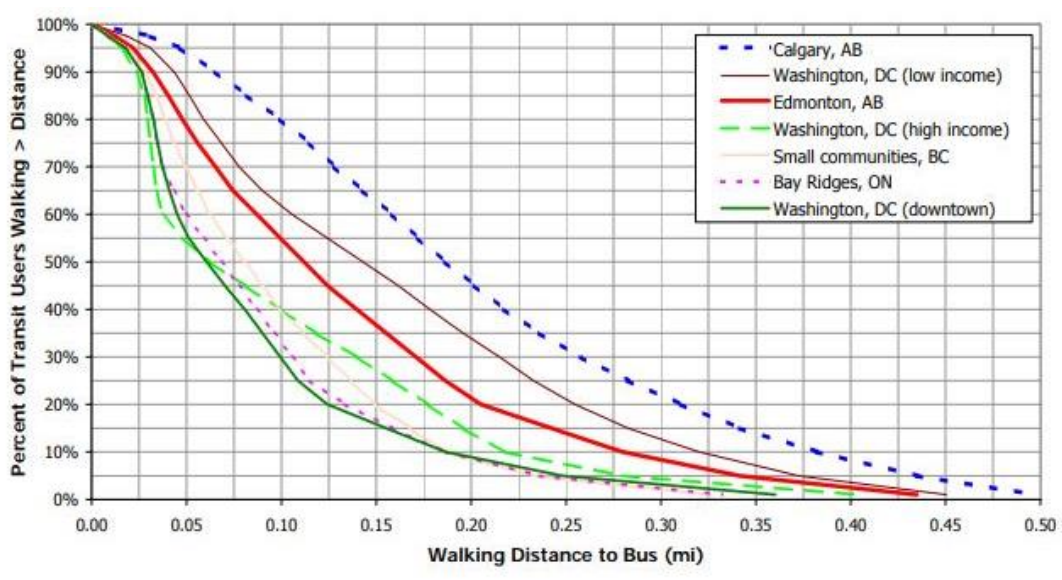

Figure 6. Walking distance to transit in North American Cities (Transportation Research Board of the National Academies, 2003)

Although the 500 meter walking distance standards give the possibility to install less bike-sharing stations than others and can be easily interpreted to be the most efficient option since it covers the larger area with a cheaper cost of establishment. But according to Washington DC's Transit Cooperative Research Program (Shown in Figure 6), the greater the walking distance needed for the public transportation, the less people willing to walk to reach the public transportation. Based on the Figure 6 . These decreasing is around $40 \%$ for each 100 meter larger from 300 meters to 500 meters ( 0.19 to 0.31 miles). If it is assumed that every country has the same average terrain and the 300 meter coverage area cover " $A$ " amounts of users, the 400 meter coverage base will cover $60 \%$ of $A$ users and $60 \%$ square of $A$ users is covered for 500 meter coverage base. Thus, installing the station with 500 meter coverage base gives the less user than another. The inference of the advantages and the disadvantages based on these three walking distance standard are summarized in Table 1.

Table 1. Summarize of the difference between the coverage areas.

\begin{tabular}{lrrr} 
Walking Distance & $300 \mathrm{~m}$ & $400 \mathrm{~m}$ & $500 \mathrm{~m}$ \\
\hline Potential stations & 809 & 541 & $\mathbf{3 5 9}$ \\
\hline Main stations & 164 & 140 & $\mathbf{1 3 1}$ \\
Feeder stations & 645 & 401 & $\mathbf{2 2 8}$ \\
\hline Integrated with road long-term plan & all & all & all \\
Lane Width > 5.5 m & all & all & all \\
Coverage Area & 47.75 & 48.07 & $\mathbf{4 8 . 0 9}$ \\
& $(99.21 \%)$ & $(99.87 \%)$ & $(\mathbf{9 9 . 9 1 \% )}$ \\
\hline Potential User & A & $\mathbf{0 , 6 ( A )}$ & $(\mathbf{0 . 6})^{2}$ (A)
\end{tabular}

\section{CONCLUSION}

In this paper there are three distribution map of potential bike-sharing station spots, based on 300 meter, $\mathbf{4 0 0}$ meter and 500 meter walking distance standard. According to the suggestion for 300 meter standard, there are 809 potential bike-sharing stations consist of 164 main stations and 645 feeder stations, while the 400 meter standard needs 541 potential stations with 140 stations serve the BRT station directly and the remaining 401 stations serve the BRT stations as the feeder. Furthermore, with 500 meter walking distance standard, the city needs 359 bike-sharing stations consist of 131 stations next to BRT stations and 228 bike-sharing feeder stations. With the coverage area is bigger than $99 \%$ for every suggestion.

Although the 500 meter coverage area gives the possibility to be more cost effective, the increasing of walking distance standard used will decrease around $40 \%$ for each 100 meter larger distance. The coverage 
area chosen need to be considered with the main purpose of the development of the bike-sharing. Since this paper suggests the development of bike-sharing system integrated with BRT in order to reduce the number of motor vehicle user. Ideally the $\mathbf{3 0 0}$ meter coverage area should be chosen because it will cover the larger amount of user than other coverage area standard suggested in this paper and it is in accordance with the Paris bike-sharing distribution standard.

\section{ACKNOWLEDGMENTS}

The author would like to acknowledge the support from lecturer in Bandung Institute of Technology, Dr. Albertus Deliar ST, MT, and from my beloved family Akinawati, Roslaini and C. Floriany. This work is also supported by Indonesia Surveyor Association, Ikatan Surveyor Indonesia (ISI).

\section{REFERENCES}

BPS-Statistics of DKI Jakarta Province. (2017). Jakarta in Figure.

DeMaio, P. (2009). Bike-sharing: History, Impacts, Models of Provision, and Future. Journal of Public Transportation, 12(4), 41-56. [Crossref]

Departemen Perhubungan Republik Indonesia. (2002). Keputusan Direktur Jenderal Perhubungan Darat no.SK.687/AJ.206/DRJD/2002.

Fishman, E., Washington, S., \& Haworth, N. (2013). Bike Share: A Synthesis of the Literature. Transport Reviews, 33(2), 148-165. [Crossref]

Han, D., Shaokun, L., Wei, L., \& Runjie, H. (2018, March). Can Private and Public Bikeshare Coexist? A Cautionary Tale from China. ITDP China.

ITDP. (2014). The Bikeshare Planning Guide. New York, US: Institute for Transportation and Development Policy.

Japan International Cooperation Agency (JICA), \& Badan Perencana Pembangunan Nasional (Bappenas) Republik Indonesia. (2004). The Study on Integrated Transportation Master Plan for Jabodetabek Phase 2. Indonesia: Almec Corporation.

Kementerian Pekerjaan Umum Republik Indonesia. (2014). Peraturan Menteri Pekerjaan Umum no. 03/PRT/M/2014.

Kodransky, M., \& Hermann, G. (2010). Europe's Parking U-Turn: From Accomodation to Regulation. Institute for Transportation and Development Policy.

Martin, E. W., \& Shaheen, S. A. (2014). Evaluating public transit modal shift dynamics in response to bikesharing: a tale of two U.S. cities. Journal of Transport Geography, 41, 315-324. [Crossref]

Mateo-Babiano, I. (2015). Public bicycle sharing in Asian cities. Journal of the Eastern Asia Society for Transportation Studies, 11, 60-74. [Crossref]

New York City Department of City Planning. (2009). Bike-Share: Opportunities in New York City.

Noland, R., \& Ishaque, M. (2006). Smart Bicycles in an Urban Area: Evaluation of a Pilot Scheme in London. Journal of Public Transportation, 9(5), 71-95. [Crossref]

Shaheen, S. A., Cohen, A. P., \& Martin, E. W. (2013). Public Bikesharing in North America. Transportation Research Record: Journal of the Transportation Research Board, 2387(1), 83-92. [Crossref]

Sustainability Management Capstone. (2013). C40 Cities in Action: How Bike-Share and BRT are Accelerating across the World. New York: Columbia University.

Transportation Research Board of the National Academies. (2003). Transit Capacity and Quality of Service: Manual. Washington DC.

United Nations Department of Economic and Social Affairs. (2011). Bicycle-Sharing Schemes: Enhancing Sustainable Mobility in Urban Areas. New York: International Road Federation 9th session.

World Bank. (1987). Bus Services: Reducing Cost and Rising Standards. Washington DC: The World Bank. 